06,11

\title{
Структурная эволюция молекулярного сегнетоэлектрика хлорида диизопропиламмония (DIPAC)
}

\author{
() Н.И. Ускова ${ }^{1,2}$, Е.В. Чарная ${ }^{1}$, Д.Ю. Подорожкин ${ }^{1}$, С.В. Барышников ${ }^{3,4}$, И.В. Егорова ${ }^{3}$, А.Ю. Милинский \\ ${ }^{1}$ Санкт-Петербургский государственный университет, \\ Санкт-Петербург, Россия \\ ${ }^{2}$ Санкт-Петербургский государственный университет аэрокосмического приборостроения, \\ Санкт-Петербург, Россия \\ ${ }^{3}$ Благовещенский государственный педагогический университет, \\ Благовещенск, Россия \\ ${ }^{4}$ Амурский государственный университет, \\ Благовещенск, Россия \\ E-mail: charnaya@mail.ru
}

Поступила в Редакцию 30 января 2020 г.

В окончательной редакции 30 января 2020 г.

Принята к публикации 4 февраля 2020 г.

Исследовались изменения структуры нового молекулярного сегнетоэлектрика хлорида диизопропиламмония $\left(\mathrm{C}_{6} \mathrm{H}_{16} \mathrm{ClN}\right.$, DIPAC), происходящие при комнатной температуре, методами ядерного магнитного резонанса (ЯМР) высокого разрешения (CP-MAS) и рентгеноструктурного анализа. Измерения методом ЯМР проводились на ядрах ${ }^{13} \mathrm{C}$. В зависимости от времени и термообработки наблюдались моноклинная сегнетоэлектрическая и орторомбическая неполярная фазы, а также их сосуществование. Показано, что полярная модификация DIPAC при комнатной температуре трансформируется со временем в неполярную орторомбическую структуру.

Ключевые слова: хлорид диизопропиламмония, DIPAC, органические сегнетоэлектрики, ${ }^{13} \mathrm{C}$ ЯMP, CP-MAS, фазовый переход, структурная эволюция.

DOI: 10.21883/FTT.2020.07.49472.016

\section{1. Введение}

Органические сегнетоэлектрики проявляют все фундаментальные свойства, присущие неорганическим сегнетоэлектрикам $[1,2]$, и обладают такими преимуществами, как экологическая безопасность и легкий вес. Однако известные до недавнего времени органические полярные материалы имели низкие температуры фазовых переходов и слабую спонтанную поляризацию. Эти недостатки были преодолены в последние годы, когда в ходе систематического изучения молекулярных сегнетоэлектриков было обнаружено несколько органических соединений сходного состава с достаточно высокой температурой Кюри и значительной спонтанной поляризацией [3-5]. Первыми полярные свойства были выявлены в хлориде диизопропиламмония $\left(\mathrm{C}_{6} \mathrm{H}_{16} \mathrm{ClN}\right.$, DIPAC) с температурой Кюри $T_{c}=440 \mathrm{~K}$ и спонтанной поляризацией $P_{s}=8.2 \mu \mathrm{C} / \mathrm{cm}^{2}$ [3]. Рентгеноструктурные исследования показали, что при комнатной температуре DIPAC может находиться в одной из морфологических фаз с ромбической симметрией $P 2_{1} 2_{1} 2_{1}$ [6] или с моноклинной симметрией $P 2_{1}$ [3]. В конкретных случаях структура зависит от условий синтеза и температурной предыстории. Сегнетоэлектрической является фаза $P 2_{1}$, из которой DIPAC переходит в параэлектрическую фазу с симметрией $P 2_{1} / m$ при $T_{c}$. Диэлектрические исследования подтвердили сегнетоэлектрическую природу структурного фазового перехода, при котором наблюда- лась классическая диэлектрическая аномалия [3]. Выявленные свойства делают хлорид диизопропиламмония перспективной альтернативой перовскитным сегнетоэлектрикам.

C момента открытия сегнетоэлектричества в DIPAC проводились различные исследования полярной фазы [7-11]. Однако эти исследования не затрагивали проблему стабильности сегнетоэлектрической модификации при комнатной температуре в течение длительного времени. Ввиду наблюдаемого полиморфизма DIPAC вопрос о возможной трансформации его структуры со временем требует детального изучения с точки зрения перспектив практических применений.

В настоящей статье представлены результаты исследований поликристаллического DIPAC методами ядерного магнитного резонанса (ЯМР) и порошковой рентгеновской дифракции при комнатной температуре с целью анализа фазового состояния в зависимости от времени и термообработки. ЯМР позволяет исследовать материалы на микроскопическом уровне и дает ценную информацию о структурных изменениях при фазовых переходах [12].

\section{2. Образцы и эксперимент}

Кристаллический хлорид диизопропиламмония был получен реакцией диизопропиламина с $30 \%$ водным 
раствором $\mathrm{HCl}$ с последующей перекристаллизацией в метиловом спирте. При комнатной температуре хлорид диизопропиламмония кристаллизовался с образованием моноклинной кристаллической решетки с пространственной группой $P 2{ }_{1}$. Это подтверждают данные порошковой рентгеновской дифракции, полученные непосредственно после синтеза с использованием рентгеновского дифрактометра Bruker D8 Discover с излучением $\mathrm{Cu} K_{\alpha}(1.5408 \AA)$. Структура согласуется с базой данных ICDD, код 00-009-0589. Моделирование полученного рентгеновского спектра DIPAC дает параметры элементарной ячейки $a=7.66 \AA, b=7.947 \AA, c=7.759 \AA$ и $\beta=114.87^{\circ}$, которые также соответствуют рентгеновским результатам, представленным в [3].

Для измерений использовали два образца. Образец 1 представлял собой синтезированный кристаллический порошок DIPAC. Образец 2 был приготовлен в виде таблетки диаметром 12 и толщиной $1.5 \mathrm{~mm}$, спрессованной из кристаллического порошка DIPAC под давлением $6000-7000 \mathrm{~kg} / \mathrm{cm}^{2}$.

Измерения методом ЯМР проводились в условиях вращения под магическим углом (MAS) на импульсном спектрометре Bruker Avance 400 при комнатной температуре с использованием датчика MAS WVT. Скорость вращения составляла $4 \mathrm{kHz}$. Для получения спектра ЯМР применялась методика переноса поляризации от протонов к изотопу углерода ${ }^{13} \mathrm{C}(\mathrm{CP}$, кросс-поляризация). В качестве референса брался сигнал ЯMP от изотопа ${ }^{13} \mathrm{C}$ в TMS (тетраметилсилан) [13]. Для получения рентгеновских спектров использовался дифрактометр, описанный выше.

\section{3. Результаты и обсуждения}

На рис. 1 представлены спектры ЯМР ${ }^{13} \mathrm{C}$, полученные при комнатной температуре для образца 1 в разное время в течение четырнадцати месяцев. Первая серия измерений была начата через две недели после синтеза образцов. Спектры снимались в течение месяца. До и между измерениями образец хранился при комнатной температуре в лабораторных условиях. Полученные за это время спектры ЯМР полностью воспроизводились. Пример спектра ЯМР показан на рис. $1, a$. Аналогичные измерения проводились и для образца 2 , который также выдерживался при комнатной температуре. Для этого образца были получены спектры ЯМР, совпадающие со спектром, приведенным на рис. $1, a$.

Как видно из рис. $1, a$, спектр ЯМР демонстрирует наличие пяти хорошо различимых линий, из которых четыре находятся в низкочастотной части спектра близко друг к другу, а одна линия сдвинута в высокочастотную область. При этом интенсивности одиночной линии и линий квадруплета соотносятся как $2: 1: 1: 1: 1$. Положение и интенсивность линий в спектре приведены в таблице. Известно, что при комнатной температуре в структуре DIPAC имеются шесть кристаллографически неэквивалентных положений углерода: два углерода в

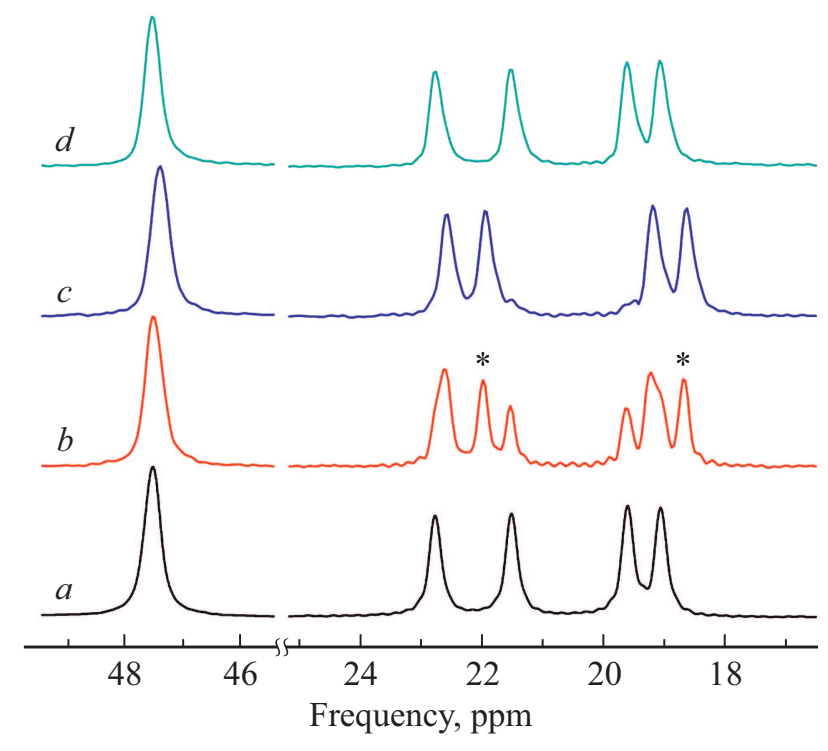

Рис. 1. Спектры ${ }^{13}$ C CP-MAS NMR DIPAC (образец 1) при комнатной температуре, полученные: $a-$ после синтеза, $b-$ через шесть месяцев, $c$ - через четырнадцать месяцев, $d-$ через четырнадцать месяцев (после нагрева).

группах $-\mathrm{CH}-$ и четыре углерода в группах $-\mathrm{CH}_{3}$ [3]. Это позволяет, следуя работе [11], приписать наблюдаемый квадруплет в низкочастотной области спектра углеродам в группах $-\mathrm{CH}_{3}$. Линия ЯМР на частоте $47.5 \mathrm{ppm}$ соответствует двум углеродам из группы $-\mathrm{CH}-$, частоты ЯМР которых близки, что приводит к слиянию двух линий в одну. Соотношение интенсивностей линий спектра согласуется с такой интерпретацией спектра. Поскольку согласно данным рентгеновской дифракции образцы имели моноклинную структуру $P 2_{1}$, то показанный на рис. 1, $a$ спектр характерен для полярной фазы DIPAC.

Через шесть месяцев снова были проведены измерения методом ЯМР образца 1. Как и в первой серии измерений, спектры ЯМР полностью воспроизводились при повторных экспериментах. Однако вид спектров значительно изменился по сравнению со спектрами, полученными в первой серии. Подчеркнем, что между

Положение $\delta_{i s o}$ и интенсивность $I$ линий в спектрах ЯМР для образца 1 DIPAC

\begin{tabular}{cc|cc|cc}
\hline \multicolumn{2}{c|}{ После синтеза } & \multicolumn{2}{|c|}{ Через 6 месяцев } & \multicolumn{2}{c}{ Через 14 месяцев } \\
\hline$\delta_{\text {iso }}, \mathrm{ppm}$ & I, r.u. & $\delta_{\text {iso }}, \mathrm{ppm}$ & I, r.u. & $\delta_{\text {iso }}, \mathrm{ppm}$ & $I$, r.u. \\
\hline 47.5 & 2 & 47.5 & 3.4 & 47.4 & 2.2 \\
22.8 & 1 & 22.6 & 1.6 & 22.6 & 1.0 \\
& & 21.9 & 1.0 & 21.9 & 1.0 \\
21.5 & 1 & 21.5 & 0.6 & 21.5 & 0.1 \\
19.6 & 1 & 19.6 & 0.6 & 19.6 & 0.1 \\
19.1 & 1 & 19.2 & 1.6 & 19.2 & 1.0 \\
& & 18.6 & 1.0 & 18.6 & 1.0
\end{tabular}




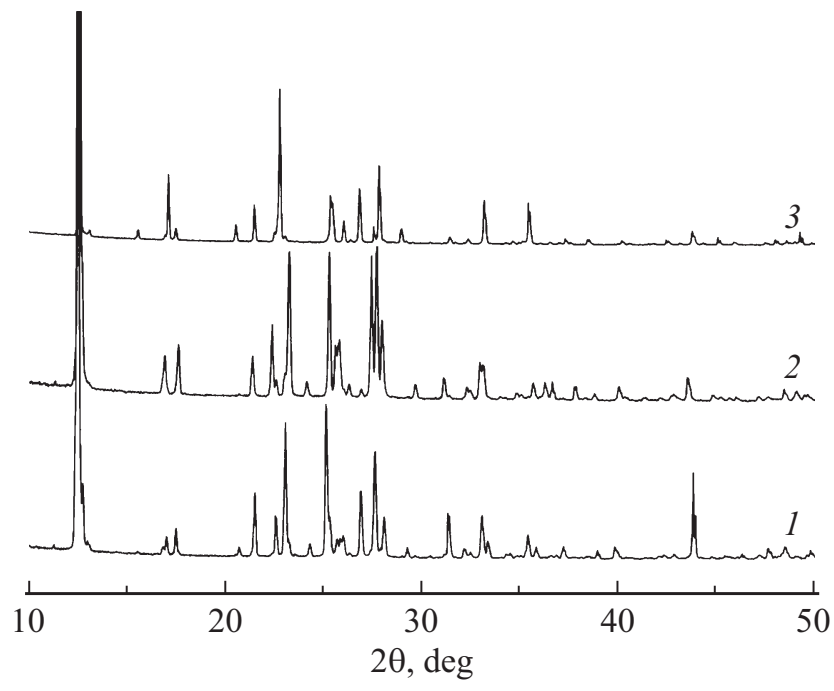

Рис. 2. Рентгеновские спектры для DIPAC, полученные при комнатной температуре: 1 - образец 1 через четырнадцать месяцев после синтеза до нагрева, 2 - образец 1 через четырнадцать месяцев после синтеза после нагрева, 3 образец 2 через одиннадцать месяцев после синтеза.

измерениями первой и второй серий образцы выдерживались при комнатной температуре. Пример спектра, полученного через шесть месяцев, показан на рис. $1, b$. На этом рисунке видно, что кроме пяти линий, присутствовавших в спектре на рис. 1, $a$, наблюдаются еще две хорошо различимые линии, отмеченные звездочкой. Кроме того, линии на частотах 47.5, 22.6 и 19.2 ppm заметно уширяются, а их форма искажается. Положение и интенсивность линий в спектре на рис. $1, b$ приведены в таблице. Очевидно, что появление дополнительных линий в спектре и искажение части линий являются следствием формирования второй структурной модификации DIPAC в результате фазового перехода. Из таблицы следует, что интенсивность дополнительных линий в низкочастотной области спектра больше, чем интенсивность линий на частотах 21.5 и $19.6 \mathrm{ppm}$, которые соответствуют полярной моноклинной фазе DIPAC. При этом, интенсивности линий на частотах 47.5, 22.6 и $19.2 \mathrm{ppm}$ согласуются с предположением, что эти линии принадлежат как спектру для полярной моноклинной фазы, так и спектру для второй структурной модификации. В частности, линия в высокочастотной области спектра представляет собой наложение двух линий, принадлежащих полярной структуре, и двух линий, обусловленных появлением второй модификации DIPAC.

Через четырнадцать месяцев после синтеза образец 1 был снова исследован при комнатной температуре методами ЯМР и рентгеновской дифракции. Рентгеновский спектр показан на рис. $2(1)$. В спектре присутствует несколько слабых линий от DIPAC в моноклинной фазе, но основные линии спектра соответствуют ромбической фазе $P 22_{1} 2_{1} 2_{1}$ с постоянными решетки $a=7.835 \AA$, $b=8.263 \AA, c=13.274 \AA$, которые хорошо согласуются с базой данных ICDD и с рентгеновскими данными, полученными в [6]. Таким образом, можно говорить о фазовом переходе из сегнетоэлектрической моноклинной фазы в неполярную ромбическую, который почти полностью закончился в образце 1 за четырнадцать месяцев, прошедших после его синтеза.

Спектр ЯМР, наблюдаемый в то же время, представлен на рис. $1, c$. Положение и интенсивность линий в спектре на рис. 1,c сведены в таблице. Сравнение с данными ЯМР, приведенными на рис. $1, a, b$, показывает, что этот спектр, как и спектр, полученный через шесть месяцев после синтеза, демонстрирует присутствие двух кристаллических фаз. Слабые линии, например, на частотах 21.5 и $19.6 \mathrm{ppm}$, принадлежат моноклинной фазе $P 2_{1}$. Положения интенсивных линий совпадают с положениями дополнительных линий, появившихся через шесть месяцев хранения образца 1. Из рис. $1, c$ видно, что новая фаза DIPAC, сформировавшаяся в результате временной эволюции за четырнадцать месяцев, является доминирующей. Полученный результат полностью коррелирует с рентгеновскими данными. Это позволяет приписать основные линии в спектре ЯМР на рис. 1, $c$ и дополнительные линии в спектре на рис. $1, b$ ромбической неполярной фазе $P 22_{1} 2_{1} 2_{1}$. Спектр для ромбической фазы состоит из пяти линий, как и спектр для полярной моноклинной модификации, но линии в спектре заметно смещены, что делает возможным идентификацию кристаллической структуры DIPAC по данным ЯМР.

Для проверки возможности восстановления полярной моноклинной фазы при термообработке образец 1 был нагрет до температуры $450 \mathrm{~K}$, а затем снова охлажден до комнатной температуры. Спектр ЯМР, снятый при комнатной температуре после нагрева, полностью совпадал со спектром, который наблюдался после синтеза (см. рис. $1, d)$. Положение и интенсивность линий совпадали со значениями в первом столбце таблицы. Это доказывает, что весь образец находится в моноклинной фазе $P 2_{1}$. Со спектром ЯМР полностью согласуется рентгеновский спектр, показанный на рис. 2(2). Он совпадает с рентгеновским спектром, полученным после синтеза DIPAC, и соответствует моноклинной структуpe $[3,11]$.

Образец 2, представляющий собой спрессованную таблетку из кристаллического порошка DIPAC, исследовался методом порошковой рентгеновской дифракции через одиннадцать месяцев после синтеза, в течение которых он хранился при комнатной температуре. Соответствующий спектр показан на рис. 2 (3). Линии спектра соответствуют ромбической структуре с симметрией $P 2{ }_{1} 22_{1} 2_{1}$. Таким образом, проведенные измерения показывают, что в спрессованном порошке DIPAC трансформация структуры при комнатной температуре из моноклинной $P 2_{1}$-фазы в ромбическую происходит несколько быстрее, чем в неспрессованном кристаллическом порошке. Действительно, образец 2 
уже через одиннадцать месяцев после синтеза полностью перешел в ромбическую модификацию, тогда как образец 1 частично оставался в моноклинной фазе через четырнадцать месяцев после синтеза. Разная скорость трансформации структуры в двух образцах, возможно, обусловлена механическими напряжениями, возникающими при прессовке.

\section{4. Заключение}

Проведенные исследования показали, что поликристаллический хлорид диизопропиламмония подвержен старению. Со временем при комнатной температуре происходит структурный фазовый переход с медленной кинетикой, при котором исходная полярная моноклинная фаза $P 2_{1}$ переходит в неполярную ромбическую фазу $P 2{ }_{1} 2{ }_{1} 2$. Трансформация структуры DIPAC проявляется в изменении спектров ЯМР ${ }^{13} \mathrm{C}$ и рентгеновской дифракции. После термообработки (нагрева выше $440 \mathrm{~K}$ ) DIPAC возвращается в сегнетоэлектрическую фазу.

\section{Благодарности}

Измерения проводились на оборудовании Научного парка Санкт-Петербургского государственного университета.

\section{Финансирование}

Работа выполнена при поддержке Российского фонда фундаментальных исследований, грант № 19-29-03004.

\section{Конфликт интересов}

Авторы заявляют, что у них нет конфликта интересов.

\section{Список литературы}

[1] M. Owczarek, K.A. Hujsak, D.P. Ferris, A. Prokofjevs, I. Majerz, P. Szklarz, H. Zhang, A.A. Sarjeant, C.L. Stern, R. Jakubas, S. Hong, V.P. Dravid, J.F. Stoddart. Nature Commun. 7, 13108 (2016).

[2] M. Owczarek, K.A. Hujsak, D.P. Ferris. Nature Commun. 7, 357 (2016).

[3] D.-W. Fu, W. Zhang, H.-L. Cai, J.-Z. Ge, Y. Zhang, R.-G. Xiong. Adv. Mater. 23, 5658 (2011)

[4] D.-W. Fu, H.-L. Cai, Y. Liu, Q. Ye, W. Zhang, Y. Zhang, X.-Y. Chen, G. Giovannetti, M. Capone, J. Li, R.-G. Xiong. Science 339, 425 (2013).

[5] A. Piecha, A. Gagor, R. Jakubas, P. Szklarz. Cryst. Eng. Commun. 15, 940 (2013).

[6] P. Prince, J.A. Miller, F.R. Fronczek, R.D. Gandour. Acta Cryst. C 46, 336 (1990).

[7] T. Apih, V. V̌agar, J. Seliger. J. Phys. Chem. C 120, 6180 (2016).

[8] C. Jiang, W.-Y. Tong, H. Lin, C. Luo, H. Peng, C.-G. Duan. Phys. Status Solidi A 214, 1700029 (2017).
[9] L. Louis, K.C. Pitike, A. Ghosh, S. Poddar, S. Ducharme, S.M. Nakhmanson. J. Mater. Chem. C 6, 1143 (2018).

[10] S.V. Baryshnikov, E.V. Charnaya, A.Y. Milinskiy, V.A. Parfenov, I.V. Egorova. Phase Transit. 91, 293 (2018).

[11] N.I. Uskova, E.V. Charnaya, D.Y. Podorozhkin, S.V. Baryshnikov, A.Y. Milinskiy, I.V. Egorova. J. Phys.: Condens. Matter 31, 505404 (2019).

[12] M.E. Lines, A.M. Glass. Principles and applications of ferroelectrics and related materials. Oxford Clarendon Press, N. Y., Oxford Univ. Press, 2001.

[13] R.K. Harris, E.D. Becker, S.M. Cabral de Menezes, R. Goodfellow, P. Granger. Pure Appl. Chem. 73, 1795 (2001).

Редактор К.В. Емщев 